\title{
LA REDEFINICIÓN DEL PAPEL DE LA EMPRESA EN LA SOCIEDAD
}

\author{
REDEFINING THE ROLE OF BUSINESS IN SOCIETY
}

Vicente Sánchez Jiménez

Universidad Complutense. Madrid. España/Spain

vicentes@pdi.ucm.es

Recibido/Received: 22/02/2015

Modificado/Modified: 24/04/2015

Aceptado/Accepted: 08/09/2015

\section{RESUMEN}

La definición de la empresa como una unidad de organización dedicada a actividades industriales, mercantiles o de prestación de servicios con fines lucrativos lleva aparejado el vínculo indisoluble entre la misma y la sociedad en la que se desarrolla. Si bien, tal connotación no permite entrever cuales son las funciones anexas que cualquier proyecto empresarial necesita para llevar a cabo su principal objetivo, el beneficio económico. Este artículo pretende poner de manifiesto cómo las empresas se han visto obligadas a adentrarse en los requerimientos sociales actualmente existentes para poder seguir manteniendo una alta competitividad en sus tradicionales espacios. Es por ello, que se puede hablar de una redefinición en la función social de las empresas al verse enriquecida la misma con múltiples variables que hasta hace poco eran anecdóticas o simplemente impensables.

\section{PALABRAS CLAVE}

Empresa, contexto social, grupos de interés, conducta moral, globalización.

\section{SUMARIO}

1. Introducción. 2. La función de la empresa en la sociedad. 3. La redefinición del vínculo empresa y sociedad. 4.- La teorización de la responsabilidad social empresarial. 5. Conclusión. Bibliografía.

\begin{abstract}
A definition of the firm as a unit of organization for industrial, commercial or services with profit carries with it the inextricable link between itself and the society in which it operates. Although such connotation does not allow to glimpse what the associated functions are that any business project needs to carry out its primary objective, the economic benefit. This article aims to highlight how companies have been forced to venture into the existing order to continue to maintain high competitiveness in its traditional social space requirements. It is why we can speak of a redefinition of the social role of business to be enriched it with many variables that until recently were anecdotal or simply unthinkable.
\end{abstract}

\section{KEYWORDS}

Business, social context, stakeholders, moral behavior, globalization.

\section{CONTENTS}

1. Introduction. 2. The role of business in society. 3. Redefining the link business and society. 4 . The theorization of corporate social responsibility. 5. Conclusion. References. 


\section{INTRODUCCIÓN}

El escenario global en el que nos encontramos inmersos ha favorecido una fuerte expansión de las empresas, dotándolas de un poder como el que no habían tenido hasta ahora. Prueba de ello lo encontramos en los datos económicos de algunas de las mismas como ya señalaba Stiglitz (2006:240) hace una década: “en 2004, la General Motor facturó 191.400 millones de dólares, cifra mayor que el PIB de más de 148 países. En el año fiscal 2005, los grandes almacenes Wal-Mart tuvieron unos ingresos de 285.200 millones de dólares, es decir, más que el PIB de todos los países del África subsahariana”. Pero en la medida que crece la influencia de las empresas en su entorno también lo hacen, favorecidas por la misma globalización, las exigencias de la sociedad civil hacia mayores cotas de responsabilidad, lo que ha impedido a las multinacionales mirar hacia otro lado. Así lo podemos constatar por las noticias que a final de 2010 aparecen de las actuaciones de la petrolera BP a consecuencia del vertido de petróleo en el Golfo de Méjico y las peticiones de la red de grupos ecologistas al Gobierno estadounidense para que endurezca los controles a este tipo de explotaciones, a lo que se ha sumado la comunidad científica y opinión pública mundial.

El papel de la opinión pública en la toma de decisiones empresariales ha crecido considerablemente. Las movilizaciones en la década de los años 60 del pasado siglo a favor de los derechos civiles generaron cambios sustanciales en esa perspectiva, así "los activistas sociales empezaron a cuestionar el objetivo económico único de las firmas comerciales" (Robbins y Coulter, 2000:142). Se han ampliado las expectativas y demandas, exigiendo una mayor responsabilidad para con la sociedad y el entorno, como son el desarrollo económico y social en todos los países donde esté presente, y el respeto y protección al medio ambiente. Es decir, estas cuestiones se han convertido en parte de su responsabilidad y de la ética empresarial. "La responsabilidad es una parte de la ética empresarial ocupada de las condiciones que subyacen a la confianza depositada en la empresa" (García-Marzá, 2011:80).

Ante esta situación no son pocas las voces que han manifestado una interrelación directa entre el avance social y el crecimiento económico de las empresas, como así lo atestigua Stiglitz (2006:240) al afirmar que "la economía moderna ha demostrado que el bienestar social no puede maximizarse cuando las corporaciones maximizan sus beneficios por su cuenta". De hecho, la actual crisis se ha mostrado como un fiel reflejo de esta aseveración, particularmente con el ejemplo del mercado de derivados: "el sistema financiero ha acumulado una gigantesca masa de capital ficticio, pero solo ha mejorado en muy poca medida las condiciones de vida y preservación del medio ambiente. Esta crisis financiera ha permitido visualizar mucho mejor las enormes desigualdades sociales, que no han dejado de incrementarse en las últimas décadas. Es una ironía que los salarios y las primas de numerosos directores generales hayan crecido exponencialmente mientras que los beneficios de sus empresas se estancaban o descendían. La ética de estos comportamientos es claramente mejorable. La libertad de mercado no puede ser ajena a la moral social" (Delors et al., 2008).

La exigencia que la sociedad civil mantiene ante la responsabilidad que las empresas deben asumir con ella, demanda un esfuerzo por parte de estas de hacer públicas las consecuencias de sus decisiones, así como de establecer canales de comunicación con los grupos que pueden influir en su viabilidad. Se convierte en un compromiso público que ha de permitir a las empresas crear un clima de confianza, convirtiéndose así en un activo empresarial. La confianza se establece por esta vía en el resultado óptimo de la justificación pública, lo que va en proporción a la capacidad de hacer pública su responsabilidad con su entorno y la sociedad 
en su conjunto. Los "nuevos" valores sociales sobre las actitudes empresariales han encontrado su plasmación en el desarrollo de una normativa nacional, o incluso regional como en la Unión Europea, en los países desarrollados. Con ello, se visualiza la presión que la sociedad civil puede ejercer, dentro de un marco democrático, sobre las decisiones políticas y sus efectos para la conformación de la función social de las empresas.

Será, por tanto, la exigencia de reciprocidad entre empresa y sociedad el principio ético que sirva de base para la toma de las decisiones empresariales en el nuevo marco de relaciones en la sociedad democrática. Es decir, la responsabilidad empresarial a partir de ahora estará sujeta a este enfoque: "una institución es responsable cuando las decisiones, acciones y políticas que adopta, así como las consecuencias y efectos de las mismas respecto a los intereses en juego, pudieran ser aceptadas por todos los implicados y/o afectados presentes y futuros en un diálogo abierto en condiciones simétricas de participación" (Habermas, 1985:116).

Las discusiones sobre el papel de la empresa en la sociedad se han acentuado durante éste periodo de cambio, pero es cierto que debemos retrotraernos a la década de los años 50 y 60 del pasado siglo para encontrar la base teórica de la que será su dimensión actual.

\section{LA FUNCIÓN DE LA EMPRESA EN LA SOCIEDAD}

Debemos mencionar que lo que hasta ahora significaba el contrato tradicional entre empresa y sociedad se basaba en la visión casi exclusiva del crecimiento económico como base del progreso tanto privado como social. Así se constata en el pensamiento económico, concretado en las palabras de Stiglitz (2006:261): "las empresas quieren beneficios, lo cual significa que generar ingresos constituye su mayor prioridad". Efectivamente, es ésta la misión básica de cualquier empresa, obtener beneficios económicos a través de la producción de bienes y servicios. Es así como las empresas contribuirán a la sociedad mediante esta responsabilidad pública de generar riqueza.

El cambio mencionado con anterioridad reside en que las empresas, principalmente las multinacionales, se han visto presionadas por las exigencias de determinados grupos conformados desde la sociedad civil, como son los sindicatos, las organizaciones no gubernamentales,..., así como por las Administraciones Públicas e instituciones académicas. Las redes sociales se han fortalecido a nivel mundial vigilando las actuaciones de las empresas no sólo en el país donde se aloje su matriz, sino en todos los rincones del mundo, lo que ha supuesto que las empresas se vean obligadas a buscar espacios de interlocución para defender sus buenas prácticas, que hasta ahora no existían.

La defensa de actuaciones responsables por parte de las empresas se basa en las discusiones sobre el papel de la empresa en la sociedad y en si su función es meramente económica o trasciende a otras variables. De hecho el propio Stiglitz (2006:261) al igual que manifiesta que "las corporaciones están en el negocio para hacer dinero, no son hermanitas de la caridad", también refuerza la idea que las mismas "han contribuido a trasladar los beneficios de la globalización a los países en vías de desarrollo y han ayudado a elevar el nivel de vida en gran parte del mundo (...), los casi 200.000 de dólares que cada año invierten en los países en vías de desarrollo han reducido el abismo de recursos que separa a éstos países desarrollados".

Por ello, entendemos necesario definir los diferentes enfoques existentes sobre el papel de la empresa en la sociedad. Ello, además, nos conducirá a encontrar como se conforma en la 
actualidad los nexos entre ambas estructuras. Podemos agrupar en dos las líneas dominantes de interrelación: la visión liberal y la socioeconómica, cuyos máximos exponentes serán Friedman y Freeman, respectivamente. No por ello debemos olvidar que existen otras concepciones en la Economía que han ejercido una influencia trascendental durante el siglo XIX y el XX, nos referimos en concreto a la teoría desarrollada por Karl Marx y que fue fuente de inspiración de las decisiones económicas de los llamados Países del Este o comunistas, dirigidos por la Unión de Repúblicas Socialistas Soviéticas, URSS.

Para los teóricos marxistas la empresa, dentro de la fase histórica del capitalismo, en la que nos encontraríamos, representa el lugar donde se produce de forma directa la confrontación entre los intereses del empresario y los obreros. Es decir, se conforma en la práctica la lucha de clases existente en el conjunto de la sociedad, burguesía versus proletariado. La relación antagónica entre la clase capitalista y la trabajadora se basa en la explotación del segundo por el primero, la cual sólo puede ser superada por la propiedad colectiva de los medios de producción, a través de tres fases: la revolución proletaria, la dictadura del proletariado y, finalmente, la sociedad comunista. Desaparecerá en este camino las clases sociales y la historia misma llegará a su fin, no en el sentido de término, sino en la concepción del materialismo histórico.

De hecho, el ataque de Marx (2001:156) hacia la empresa capitalista del siglo XIX es tan profundo que considera a la Economía como la ciencia moral al servicio de éstas, dando soporte tanto a su creación y mantenimiento, como a las clases sociales. Este planteamiento lo podemos visualizar cuando afirma que "esta ciencia de la industria maravillosa es al mismo tiempo la ciencia del ascetismo, y su verdadero ideal es el avaro ascético, pero usurero, y el esclavo ascético, pero productivo,..., por esto la Economía, pese a su mundana y plácida apariencia, es una verdadera ciencia moral, la más moral de las ciencias,..., La autorrenuncia, la renuncia a la vida y a toda humana necesidad es su dogma moral"

La diferencia más profunda entre la visión marxista y las teorías predominantes en la actualidad sobre la función social de la empresa es que éstas últimas no se cuestionan el sistema, pues entienden que se ha conseguido una situación de consenso social en el momento presente, gracias al Pacto trabajo y capital tras la Segunda Guerra Mundial. Se rompe por esta vía, de alguna manera, con la concepción capitalista anterior a 1929, conformándose un capitalismo socialdemócrata que intenta evitar la confrontación dentro del Estado de Bienestar. Mientras que para el marxismo la empresa capitalista es la máxima expresión de la lucha de clases, el lugar de enfrentamiento de intereses antagónicos. En la visión de la responsabilidad social empresarial, las empresas se convierten en el centro de la actividad integradora de un cada vez mayor número de agentes, tanto internos como externos, y en la adaptación de las decisiones empresariales a más factores. Pasamos, pues, a definir los enfoques predominantes sobre la función social de la empresa.

El enfoque liberal, también denominado clásico, tiene en Milton Friedman (1962) su principal valedor, quien afirma que las responsabilidades sociales son individuales y no empresariales. Sus argumentos se basan en la teoría de la "mano invisible" de Adam Smith. Desde este punto de partida afirma que la única misión de las empresas es incrementar sus beneficios a través del uso eficiente de los recursos. Su responsabilidad social, por tanto, vendría aparejada a que esta misión se realizase en una competencia libre y leal.

Por su parte, el enfoque social amplía aún más la propia naturaleza de las empresas. Uno de sus principales autores es Archie Carroll (1979), para quien la empresa se articula dentro de la relación entre las diversas instituciones que integran el contexto social. De esta forma la responsabilidad de las empresas versaría sobre su comportamiento económico y legal pero también ético y discrecional. Estamos hablando, pues, de una visión holística de la empresa 
en su función de generación de riqueza y desarrollo social, al tener que ser eficiente dentro del marco legal regulatorio y de los valores sociales imperantes.

Pero si hay un posicionamiento teórico que ha influido decisivamente en lo que hoy entendemos por la responsabilidad de la empresa hacia la sociedad es el enfoque de los stakeholders, que se ha generalizado en nuestra terminología como grupos de interés. Esta visión parte de la obra de Freeman y defiende que las decisiones empresariales no sólo se orientan a la satisfacción de los accionistas, sino que han de ampliarse a todos aquellos grupos interesados por la actividad de la empresa, tales como empleados y sus organizaciones sindicales, proveedores, clientes, asociaciones de consumidores, Administraciones Públicas e instituciones reguladoras,..., es decir, cualquier grupo que pueda influir en la consecución de los objetivos de la organización. Lo cual nos conduce a la idea matriz de la teoría del autor norteamericano, que se basa en que para conseguir la maximización de sus beneficios, las empresas deben atender al entorno que las rodea disponiendo de una comunicación fluida con sus grupos de interés, que les demuestre sus buenas prácticas empresariales, de manera que reciban una respuesta positiva de la sociedad.

Pasemos a estudiar con más detenimiento cada una de estas interpretaciones.

\section{a) Friedman: la defensa de "la mano invisible"}

El autor norteamericano se muestra firme defensor de la consideración tradicional sobre la función de la empresa. Para él solamente hay una responsabilidad social en los negocios: utilizar los recursos y desarrollar actividades diseñadas para incrementar las ganancias siempre y cuando permanezcan dentro de las reglas del juego, es decir, que se dediquen a la competencia abierta y libre sin el engaño ni el fraude.

Mediante esta percepción el único objetivo de las empresas en su actividad económicaproductiva será maximizar sus beneficios respondiendo al interés de sus inversores, esto es: "hacer cuanto más dinero sea posible conforme a las normas básicas de la sociedad, tanto las legales como las costumbres éticas" (Friedman, 1990:154). Para Friedman esta idea se fortalece por la propia idiosincrasia del sistema de mercado, que legitima jurídicamente dicho objetivo, y por dejar al Estado el papel exclusivo de atender las necesidades sociales gracias a los ingresos que obtiene de los impuestos que soportan las empresas, cuanto mayor beneficios empresariales mayores ingresos para el Estado y, por lo tanto, mejora del grado de bienestar económico y social de la sociedad.

La perspectiva utilitarista de Friedman (1970) es compartida por autores como Sheldon (1923) y Levitt (1958), cuyas teorías económicas de la empresa refuerzan el interés puramente económico de los negocios. De hecho una de las posiciones centrales de los economistas neoclásicos, como vimos en el primer capítulo, ha consistido en separar los hechos económicos de las valoraciones morales o de las consideraciones políticas. Esta limitación haría posible defender que la función social de las empresas se encuentra en producir la mayor utilidad posible, lo que traerá consigo un mayor bienestar social. En otras palabras, la búsqueda exclusiva de los propios intereses permitiría un mayor beneficio que redundaría en el conjunto de la sociedad. Esto es fácilmente entendible si tenemos en consideración que desde la posición de la economía neoclásica, la mayor felicidad es asociada a la consecución de elecciones racionales encaminadas a la búsqueda egoísta individual.

Por esta razón el propio Friedman (1979a) sostiene que no puede existir una responsabilidad social de las empresas, pues los empresarios no son agentes morales sino únicamente económicos. De tal forma que es la propia dinámica de los mercados la que 
regula el compromiso de las empresas en la sociedad, pues son las decisiones de los consumidores las que determinen la viabilidad de los negocios. Así, las intromisiones en la dinámica económica lo único que ocasionan son disfunciones en el sistema que impiden un desarrollo correcto de la interconexión entre empresa y entorno social. Esto se debe a que desde la teoría utilitarista la consecución del mayor grado de eficiencia se logra debido, por una parte, a que la motivación egoísta de cada individuo permite un modelo de intercambio en el cual existe un beneficio recíproco logrando una mayor satisfacción social, y, por otra, a que estos mismos individuos actúan en base a elecciones racionales que persiguen la maximización de sus utilidades.

Efectivamente, mediante esta línea argumental el propio Friedman critica la verdadera motivación que hay detrás de muchas decisiones empresariales que dicen mantener una postura de responsabilidad social. De esta forma afirma que tras estas posturas se encuentra el intento único de lograr mayores beneficios económicos mediante prácticas de fidelidad de los consumidores y la exención de impuestos. Nos encontramos, pues, ante el fraude de la responsabilidad social, que no es más que una práctica egoísta para el propio interés, denominando beneficio social aquello que únicamente es un instrumento del beneficio de accionistas y propietarios. Friedman (1979b:543) rechaza este tipo de prácticas, pues no son otra cosa que "generar bondad como producto de los gastos justificados en su propio beneficio".

Este último es uno de los argumentos que Friedman utiliza en contra de la llamada responsabilidad social de las empresas, y evidentemente uno de los más complicados de rebatir. De hecho algunos autores como Baron (2001) distinguen entre acciones "altruistas" y acciones "estratégicas": mientras que las primeras surgen de la motivación de servir a la sociedad a pesar de ocasionar un cierto gasto, la acción se podría considerar socialmente responsable, en el caso de las segundas, que podríamos calificar de privadamente responsables, estarían encaminadas a mejorar la cuenta de resultados. Lo que es cierto es que en ambos supuesto se puede apreciar que el coste para la empresa revierta a posteriori en una serie de beneficios, tanto directos como indirectos.

Ahondando más en esta idea nos podemos encontrar, según Crowther (2004) con dos variables. Bien el cumplimiento de objetivos de responsabilidad social es una mera maniobra de imagen de la empresa, que inmersa en la moda de este tipo, pretende invertir en tener una mejor valoración en este sentido, aunque dista mucho de tener convicciones profundas sobre este particular y realiza acciones no públicas contrarias a esta filosofía; o bien, la contribución de la empresa a fines de responsabilidad social constituye una separación del verdadero objetivo de los propietarios del capital, los accionistas, por lo que se están usando sus recursos para conseguir otros fines que no son los suyos y en parte se les están detrayendo recursos de forma indebida.

Según el propio Friedman (1970) es la falta de concreción del concepto de responsabilidad aplicado a las decisiones empresariales la que trae aparejada una imprecisión analítica y, por tanto, la falta de rigor. Está claro que podemos medir el beneficio económico pero no parece tan fácil objetivar la moralidad de una buena parte de las actuaciones privadas. Es muy distinto defender que existe una responsabilidad más allá del beneficio económico, y lograr delimitar y plasmar su consistencia.

\section{b) Carroll: la función social de las empresas}

Por su parte Carroll mantiene una postura más holística de la función de las empresas en la sociedad, criticando, por tanto, la consideración de la empresa como una institución que tiene sólo responsabilidades económicas en base a tres características. Primera, esta concepción 
tan restrictiva no se corresponde con la verdadera naturaleza de las empresas, pues los efectos de estas van más allá de lo puramente económico. Segunda, no tienen en cuenta la profunda transformación social hacia una conciencia colectiva de resolución de problemas. Tercera, apartan a las empresas, como agentes sociales, de su participación en las políticas sociales, dejando esta función en exclusiva al Estado.

De esta forma Carroll (1993:34) defiende unas nuevas funciones de la empresa cuando afirma que "la empresa socialmente responsable debe esforzarse por conseguir un beneficio, obedeciendo la ley, siendo ética y siendo un buen ciudadano corporativo". La existencia de determinadas prácticas empresariales, además, facilitará la creación de expectativas de la sociedad ante las cuatro variables citadas. Nos presenta, por tanto, su propio modelo de responsabilidad empresarial, el cual se asienta en los cuatro tipos de compromisos que la sociedad espera obtener: beneficio económico, cumplimiento normativo, compromiso moral y contribución voluntaria. Es decir, las empresas poseen una responsabilidad hacia la sociedad, pues como agentes sociales deben asumir la consideración moral de responder de sus decisiones. Autores como Donalson y Dunfee (1999) se unen a esta postura, añadiendo que la empresa posee un contrato social formal con la sociedad a la que pertenece y ese contrato debe ser cumplido.

Este conjunto de elementos fue ordenado y caracterizado por Carroll (1993) en forma de pirámide. En ella los aspectos económicos son situados en la base, el siguiente nivel estaría ocupado por las cuestiones legales, más arriba se situarían los valores sociales y, por último, en la cúspide encontraríamos las actuaciones filantrópicas.

En concreto, Carroll se referirá a cada uno de estos compromisos mediante la percepción social de los mismos. El beneficio económico se conseguirá a través de maximizar la eficacia y la minimización de los recursos, además, cuanto mayor sea éste mejor será el concepto que la sociedad tenga sobre la empresa, pues la otorgará a priori una valoración positiva al referirla como más competitiva. Por su parte, el cumplimiento normativo se muestra como la responsabilidad legal de los negocios y la publicidad de ciertas cuestiones, como en el caso de la normativa española, las cuentas anuales acordes a las reglas del plan general contable. Con ello, a la generación de beneficios las empresas han de añadir la transparencia en su gestión mediante el sometimiento al imperio de la ley que regula los mercados y las obligaciones de la empresa. Aunque las responsabilidades económicas y legales incluyen normas éticas, más concretamente el compromiso moral es visto por Carroll como los comportamientos y actividades que fomentan el respeto a los valores de la sociedad. Por último, la contribución voluntaria o filantrópica estaría formada por las iniciativas discrecionales no exigidas por la ley y tampoco desde el punto de vista ético de la sociedad

Si bien es cierto que estas premisas tan tenido cierta influencia en el mundo empresarial, también lo es que en la actualidad están apartadas de las principales líneas teóricas sobre la función social de las empresas. Ello se debe a que las expectativas de las sociedades democráticas hacia las empresas no se quedan en la exigencia de mayores compromisos voluntarios, sino que llegan a la revisión paradigmática de la concepción tradicional de las mismas. Llegados a este punto la empresa deja de ser un ente ajeno al devenir de la sociedad para convertirse en una institución social que proyecte su conducta en base a unos mínimos de responsabilidad colectiva, progreso social e interés general, como así entiende Freeman (1984).

En cierta forma esta visión se sitúa más en la línea del utilitarismo desde el punto de vista ético frente al económico. Mientras que para la economía neoclásica la mayor felicidad social se logra por la búsqueda de las preferencias individuales, ejemplo de lo cual podemos citar el 
óptimo de Pareto por el cual un orden económico sólo puede mejorar sin producir mayor prejuicio a la situación de otros. Para la Ética la mayor felicidad exige a los individuos que, al decidir, traten de maximizar el bien para todos los miembros de la sociedad, como así citábamos en el caso de Aristóteles en páginas anteriores. Asimismo para los filósofos se trata de un principio universal que exige que el propio interés no se ponga por encima de los intereses de los otros.

\section{c) Freeman: el modelo de los stakeholders.}

Freeman (1984), por su parte, desarrolla la teoría de los stakeholders, o grupos de interés, como el avance de la perspectiva utilitarista hacía una perspectiva dialógica. El modelo presenta a las empresas como un agente relacionado con la sociedad, no de un modo abstracto sino a través de elementos concretos, esto es de "cualquier grupo o persona que pueda afectar o ser afectada por el logro de los objetivos de la empresa".

Esta visión de las relaciones entre empresa y sociedad tiene varias particularidades. La primera es reconocer que los stakeholders se muestran como agentes capaces de influir en la consecución de las actividades de las empresas. La segunda, concretar que la relación entre empresa y sus stakeholders es de doble dirección, ya que los grupos de interés también pueden estar afectados por las decisiones y acciones de las empresas. La tercera, que es necesario conocer ante quién es responsable la empresa. Y, la cuarta, que debido a que las empresas están compuestas por una variedad de grupos de interés de los que depende su credibilidad o legitimidad social, es necesario incorporar sus expectativas a las decisiones a tomar.

El modelo de los stakeholders se encuentra en la actualidad incorporado de forma destacada a la literatura de administración de empresas, conformándose como la piedra angular de una gran cantidad de obras sobre la gestión estratégica de negocios, en concreto desde la perspectiva de las relaciones de responsabilidad ante los grupos o individuos afectados por los objetivos de la empresa. Esto es debido a que Freeman (1984) a diferencia de Friedman defiende que la gestión sistemática de los intereses de los stakeholders es fundamental para lograr la viabilidad de cualquier proyecto empresarial en el tiempo. Para ello las empresas deben incorporar estos intereses en la dirección estratégica de la empresa, dedicando recursos que implementen actuaciones de relación con estos grupos ante la posibilidad de lograr ventajas competitivas.

Así, la dirección de la empresa logrará aunar los objetivos de la empresa con las expectativas de sus stakeholders. Sirvan como ejemplo las palabras de Hill y Jones (1996:61) al afirmar que "la empresa que asume una responsabilidad social, más allá de la maximización del beneficio para el accionista, conlleva una mejora de los resultados económicos a largo plazo. Por lo tanto, sólo se puede conseguir esta primera responsabilidad respecto al accionista, asumiendo la responsabilidad frente a los demás agentes sociales implicados en la gestión de la empresa. En conclusión, para que la empresa crezca a largo plazo es imprescindible que sustente sus procesos y productos en unos estándares éticos, que integre en su gestión y que trate de dar respuesta a las demandas de los agentes sociales a los que afecta o que le afecten".

Debido a la relevancia adquirida por la teoría de los stakeholders algunos autores han profundizado en el conocimiento de los individuos y grupos que puede afectar o ser afectados por las actuaciones de las empresas, de tal forma que en la actualidad se distingue entre stakeholders primarios y secundarios según la relación que mantenga con la empresa. Si este vínculo es formal, oficial o contractual estaríamos hablando de primarios (Clarkson, 1995), 
mientras que los secundarios serían todos aquellos que estarían fuera de esta clasificación y que no son estrictamente necesarios para el mantenimiento de la empresa (Carroll, 1993).

Dentro del grupo de stakeholders primarios, o de relación privada, encontraríamos a los accionistas, inversores, empleados, clientes y proveedores. Para el caso de los secundarios, también llamados públicos, estaríamos hablando, entre otros, de las comunidades, sus gobiernos y redes sociales, es decir "los que influyen o afectan, o son influido o afectados por la empresa; sin embargo, ellos no participan en las operaciones ni son esenciales para su supervivencia" (Rowley, 1997:887). Aun así, los stakeholders públicos tienen la capacidad de movilizar la opinión pública a favor o en contra de una empresa, perjudicando de forma directa la consecución de los objetivos empresariales.

Todos estos campos de trabajo entre empresa y sociedad traen consigo que la teoría de los stakeholders cada vez sea más extensa, de forma que encontremos nuevo elementos de análisis, como es el caso del llamado desarrollo sustentable. Su definición más extendida es la realizada por Brundtland (1987) al decir que se entiende por "el desarrollo que satisface las necesidades actuales sin comprometer la capacidad de las generaciones futuras para atender a sus necesidades futuras", afirma entre otras cosas que la empresa tiene la obligación de garantizar que sus actividades también sean ecológicamente sostenibles, convirtiendo al medioambiente, es decir, el entorno que rodea tanto a la empresa como a la sociedad civil en un nuevo stakeholder por derecho propio.

\section{LA REDEFINICIÓN DEL VÍNCULO EMPRESA Y SOCIEDAD}

Comprobamos como la revisión de la función social de la empresa ha originado toda una línea de argumentación sobre la existencia de una responsabilidad empresarial hacia la sociedad. De hecho, como se puede observar, nos encontramos ante lo que podríamos considerar una nueva definición de la función de la empresa en el marco socioeconómico. Si como atestiguan Koontz y Weilhrich (1998:62) "a principios del siglo XX la misión de las compañías privadas era exclusivamente económica”, en la actualidad a las empresas, principalmente las multinacionales, se las considera como instituciones con una importante responsabilidad moral con el conjunto de la sociedad, debido a su cada vez mayor influencia.

La empresa ha ido adquiriendo mayor capacidad para convertirse en un verdadero motor del cambio social, por cuanto sus acciones afectan de manera significativa al conjunto de la comunidad y de su entorno. Se ha pasado de una relación entre empresa y sociedad básicamente económica, en la que los cometidos de la primera con respecto a la comunidad se resumían en la producción de bienes y servicios como soporte para generar empleo y contribuir al crecimiento económico, a una perspectiva más institucional donde las empresas, consideradas como un sistema abierto, adquieren un contrato de responsabilidad con el conjunto de la sociedad directamente a través de sus stakeholders, por utilizar la conceptualización realizada por Freeman.

Este nuevo contrato entre empresa y sociedad se asienta en la convicción de que el sólo interés por el crecimiento económico como base del desarrollo tanto para la empresa como para la comunidad trae aparejados efectos indeseables que producen unos costes sociales éticamente inasumibles.

Los beneficios económicos a corto plazo pueden conllevar en el futuro efectos indeseados en el medio ambiente y problemas de salud, entre otras cosas, resultado de la manipulación de sustancias tóxicas, como así señala Buchholz (1990:6). Un caso concreto es la producción 
y comercialización del amianto y sus componentes; prohibida en los países más avanzados, por comprobarse sus efectos devastadores para la salud laboral y pública tras las movilizaciones de las organizaciones sindicales, se potencia en aquellos cuya legislación en materia de seguridad y salud laboral es más laxa, como puede ser la India. Con ejemplos como el citado podemos comprobar cómo el cambio de valores, en este caso en la defensa de la salud laboral y pública por encima de los beneficios económicos, fuerzan la modificación de las conductas empresariales por medio de las Administraciones Públicas en los sistemas democráticos más desarrollados, es decir, con la promulgación de normas, acentuándose con ello los vínculos entre economía, sociedad y política. Este hecho contrasta con la "huida" de determinados procesos productivos nocivos, caso del amianto, tanto para los trabajadores como para la sociedad en su conjunto, hacia economías emergentes.

El nuevo contrato parte del respeto al objeto tradicional de los negocios, añadiéndole aspectos más novedosos de interrelación con la comunidad. Este cambio de mentalidad en el devenir de las empresas puede ser debido a la necesidad de dar respuesta a demandas o presiones del medio social y cultural, como en los casos de las denuncias producidas por grupos de derechos humanos contra el trabajo infantil, pero también por adoptar una actitud pro-activa. Tanto la corrección de lo que se podría entender como una mala praxis, como una posición directamente más comprometida con los valores, sociales son consideradas como actuaciones de responsabilidad social.

\section{LA TEORIZACIÓN DE LA RESPONSABILIDAD SOCIAL EMPRESARIAL}

La palabra responsabilidad lleva implícita la necesidad de responder por las consecuencias de las decisiones y acciones, mientras que la palabra social nos expresa que esas decisiones y acciones afectan a otros. Es por este motivo, además, de por ser la perspectiva deontológica la corriente ética que más ha intervenido en su desarrollo, por lo que el concepto de responsabilidad social empresarial se puede considerar inicialmente como un concepto moral. La responsabilidad social ejercida por las empresas se establece como una regla por al que las iniciativas tomadas se ponen en contraposición con los fines mismos y su repercusión más allá de la propia organización. Es decir, la actividad de la empresa se evalúa bajo el prisma de estándares éticos asumidos por la sociedad y que regulan un mínimo de comportamiento social como son el respeto a los derechos humanos, entre otros.

La responsabilidad social de la empresa es concebida como voluntaria desde sus orígenes, hecho que Carrol (1979) sitúa en la década de 1970. Notemos que según la opinión del autor inglés, este particular ocurre tras lo que hemos denominado la primera gran crisis del capitalismo en el pasado siglo y es contemporánea del nacimiento de las teorías de los "fallos del Estado". La pretensión de voluntariedad otorgada a la responsabilidad social empresarial es defendida por aquellos que consideran a esta característica como fundamental para lograr una mayor eficiencia en las actuaciones de respuesta de las organizaciones, facilitando una mayor capacidad de adaptación a las diversas realidades sociales. Esta idea es reforzada por la opinión de que una regulación puede traer consigo situaciones que impidan la libre actuación empresarial (Michael 2003).

Será a partir de la década de 1960 cuando reciba una enorme atención porque en ellos emergieron asuntos sustanciales que modificaron la exigencia de las sociedad ante las empresas: los derechos de ciudadanía, la exigencia de igualdad de trato, la lucha contra la contaminación, la protección del medio ambiente, la salud y seguridad laboral y los derechos de los consumidores, por citar los más relevantes. De hecho, las que podemos considerar 
como las organizaciones sociales que ejercen el contrapeso al poder empresarial desde la perspectiva clásica, nos estamos refiriendo a los sindicatos, alegan que la responsabilidad social de la empresa no es un tema nuevo para ellos, por cuanto "el sindicalismo confederal, históricamente, ha exigido siempre el reconocimiento de la dimensión social de la empresa y ha reconocido la necesidad de que la empresa, la economía y el mercado, sean objeto del gobierno democrático de la sociedad, y de que la economía esté, efectivamente, al servicio de las personas y las necesidades sociales" (CCOO, 2009).

Dos escuelas de pensamiento, el concepto de libre mercado y el enfoque orientado socialmente, buscarán explicar la función de la empresa en la sociedad y, por ende, como apuntábamos en los casos concretos de Friedman y Freeman, aclarar en qué consiste su responsabilidad social empresarial. Será esta segunda posición, junto con la teoría de los stakeholders, la que más ha influido en la configuración actual del concepto, basándose en la noción de que las empresas tienen responsabilidad más allá de sus obligaciones legales.

Como muestra de la importancia del pensamiento orientado socialmente se ha afirmado que la responsabilidad social empresarial es la obligación directiva de actuar para proteger y mejorar el bienestar de la sociedad en su conjunto y el interés de la organización (Maguire, 1963). Esta definición se ha extendido hasta sugerir que la responsabilidad social no está limitada por el comportamiento de las personas, sino que también se refiere al impacto de las acciones institucionales en todo el sistema social (Davis, 1979). Comprobamos como la responsabilidad social de las empresas sería la acción que va más allá del cumplimiento minimalista de la ley.

De esta forma, y siguiendo la definición formulada por Carroll (1979:504), podemos interpretar que "la responsabilidad social de la empresa abarca las expectativas económicas, legales, éticas y filantrópicas de las sociedad, en un momento determinado en el tiempo". Cuatro categorías básicas de obligaciones que van a conformar, por decirlo así, el concepto total o integral de responsabilidad, asumiendo, por tanto, que cada una no excluye a la otra.

Partiendo que la responsabilidad básica, que justifica la creación y el devenir de toda empresa, es de naturaleza económica, debemos añadir otros tres aspectos. Estos son: la responsabilidad legal impuesta desde el marco regulatorio, que la sociedad espera ser cumplida por la empresa; las obligaciones morales que aun no estando reguladas son esperadas por la sociedad en el comportamiento empresarial; y la responsabilidad de tipo discrecional, en las que estarían inmersas las aportaciones filantrópicas y las donaciones realizadas a causas sociales.

En esta línea debemos realizar ciertas matizaciones. La primera es que la responsabilidad social de la empresa no debe ser concebida como un ente al margen de la propia actividad económica o en todo caso como un agregado a esta, sino que en la medida que trata de dar respuesta de las acciones empresariales a la sociedad se configura como una práctica más del día a día y modifica la cultura organizativa como medio para cometer los cambios necesarios en la conducta empresarial. La segunda particularidad está íntimamente ligada con lo expresado anteriormente, pues dar respuesta a las expectativas sociales significa rendir cuentas de su actividad, así como de gestionar su compromiso social. En tercer lugar la responsabilidad social es entendida como una obligación moral hacia el conjunto de la sociedad, expresada desde la relación con los grupos de interés que le son propios a cada proyecto empresarial. En este sentido debemos hablar tanto del ámbito interno propio de la empresa, un ejemplo claro lo encontramos en sus trabajadores, como en el ámbito exterior a la misma, entre otros podemos citar las Administraciones Públicas y las comunidades locales. Sobre este particular debemos mencionar que Carroll (1979) sostiene que la 
separación entre el ámbito interno y el externo de la responsabilidad social de las empresas sólo tiene un propósito conceptual, ya que en la realidad las empresas deben tomar a diario decisiones que afectan tanto a su componen te interno como al externo y, por tanto, esta variable no existe como tal, no habiendo diferencia entre las actuaciones circunscritas a la propiedad de la empresa con aquellas de propiedad social.

Igualmente, la responsabilidad social debe ser entendida como la promoción, por parte de las empresas, de una mejor calidad de vida de la sociedad, en el camino de conseguir unas cuotas mayores de bienestar social, lo que supone una dificultad para su cuantificación práctica y concreta por ser estos aspectos en gran medida intangibles y de difícil medición. Por último, debemos entenderla con una actitud colectiva es decir de la institución en su conjunto y no de actuaciones individuales asociadas a las personas con poder de decisión. Este hecho será más fácil cuanto más impregnada esté la cultura de la organización de los valores sociales, modificando así objetivos y estrategias de la organización.

Desde los años noventa las actuaciones de responsabilidad social empresarial se han ido ligando a cuestiones como la ética empresarial, la teoría de los grupos de interés, el comportamiento social de la empresa y el concepto de ciudadanía empresarial, haciendo de este particular un campo cada vez más amplio de interrelaciones y, por tanto de mayor dificultad en su concreción. En los últimos años cuestiones como la cooperación al desarrollo y el comercio justo, la promoción interna del voluntariado, la lucha contra la exclusión social (contratación de personas en situación de marginalidad), se han ido sumando al papel que la empresa debe asumir como institución social. Por este motivo, volvemos a referirnos a la responsabilidad social como un nuevo contrato moral de la empresa con la sociedad. Se plasma así el papel que la empresa asume como un agente social más.

Al reforzarse las imbricaciones entre diferentes entidades, principalmente empresas, sindicatos y organizaciones del tercer sector, se están ampliando las redes de contacto y colaboración en la sociedad. Bajo la perspectiva de un mismo compromiso social, de unos mismos objetivos, la responsabilidad social empresarial forma parte inexorablemente del capital social en los países más desarrollados. Es decir, lo podemos sintetizar como "la búsqueda del modo en que los actores sociales trabajen juntos, permitiéndoles anticipar los cambios y gestionar las reestructuraciones" (CES, 2005:1).

Bajo el prisma del capital social la responsabilidad empresarial es una experiencia de los países desarrollados casi en exclusiva. Esto es debido entre otras cuestiones a que ha sido en estos países donde se ha alcanzado una conciencia ciudadana con nuevos valores sociales en las últimas décadas. Es decir, a través de un mayor grado de civismo en el que también se van articulado las actividades empresariales. Conciencia cívica que se expresa en el intercambio positivo entre empresas y sociedad, por cuanto la sociedad percibe que las empresas actúan conforme a unos valores comunes la ciudadanía responderá de forma satisfactoria garantizando, por ejemplo, un buen clima laboral o la fidelidad a la hora de comprar un producto. Es en base a este juego recíproco de expectativas donde podemos hablar de contrato moral. Por este motivo la responsabilidad social empresarial también ha sido entendida como agente de control que ayude a solucionar los posibles daños causados por las empresas en su actividad (Buchholz, 1991), potenciando, además, la acumulación de capital social en aquellas comunidades donde se articule.

Un contrato social que se ha visto potenciado por las tecnologías de la comunicación y la información, que han permitido que determinadas acciones y efectos perniciosos social o medioambientalmente de la actividad empresarial puedan ser rápidamente conocidos a nivel mundial y provocar respuestas sociales inmediatas, tanto mediáticas como, en ocasiones, políticas, exigiendo la adopción de medidas que penalizan, compensen por daños causados y, 
en su caso, motiven cambios institucionales. Como el comentado caso de Infact vs Nestlé o más recientemente el vertido de petróleo en el Golfo de Méjico por la empresa británica BP.

En este contexto entendemos que la responsabilidad social empresarial se puede definir como el compromiso asumido de actuar de forma ética conforme a los valores sociales en la consecución de los objetivos económicos propios del proyecto empresarial. En otras palabras, desarrollar el proyecto empresarial, creando valor financiero respetando las demandas de sus grupos de interés y de la ciudadanía en su conjunto. Ello implica que la responsabilidad social empresarial se sitúe tanto como el instrumento para evitar posibles confrontaciones en la actividad cotidiana de la empresa, como el mecanismo por el cual las compañías incluyen los asuntos sociales y ambientales en su actividad.

La responsabilidad social así entendida supera la concepción clásica del objetivo empresarial y el cumplimiento de la regulación vigente, incorporando la respuesta positiva a las demandas sociales, entendidas estas por sus grupos de interés. Por este mecanismo la empresa no solo desarrolla acciones cuyo único fin sea el beneficio económico o el cumplimiento de las normas vigentes sino que la empresa al ir ampliando su influencia en el ámbito económico, social y político también ha de dar respuesta a su triple responsabilidad; económica, social y ambiental (CCE, 2001). En la actualidad de la empresa se demanda la creación de riqueza, el respeto a los valores sociales y el desarrollo sostenible. Es decir, "la responsabilidad de las empresas por sus impactos en la sociedad" (CE, 2011:7).

Desde esta perspectiva la responsabilidad social empresarial abarcará un amplio abanico de iniciativas, desde las puramente discrecionales, como son las actividades de patrocinio y las de acción social, hasta aquellas dirigidas a reducir el riesgo de reputación o de marca, en este caso podemos citar la mejora en las relaciones laborales y los intentos por reducir el impacto de su actividad en el medio ambiente. A estas últimas debemos sumar los programas que bajo el prisma de la responsabilidad social llevan a cabo la tarea de generar nuevos productos y procesos para satisfacer las demandas de sus grupos de interés y de la sociedad en general, entre las que encontramos las inversiones en I+D+i. Esta concepción de responsabilidad social va más allá de la simple respuesta a la sociedad, situándose en un plano de diferenciación con respecto a otras iniciativas empresariales y otorgando un valor de diferenciación que pueda acarrear una ventaja competitiva. De hecho, incluso en los actuales momentos de inestabilidad económica "lo que esta crisis ha puesto de manifiesto es que la responsabilidad social corporativa es un fenómeno que ha llegado para quedarse" (Martín y Navarro, 2014:28).

De esta forma la responsabilidad social empresarial se sitúa en el plano proactivo frente a las demandas de la ciudadanía, al aportar un mayor valor de respuesta y, por tanto, la posibilidad de crear valor por encima de sus competidores. La reducción de los efectos negativos de las externalidades generadas por la empresa es a todas luces positiva para la viabilidad empresarial. En todo caso se puede admitir que la función social de la empresa puede ir más allá del cumplimiento de los cuatro factores de la pirámide de Carroll (1979), adoptando programas que afecten a sus estrategias y líneas de negocio en la perspectiva que nos ofrece Freeman (1984). En efecto, la responsabilidad social empresarial se mostraría como un elemento de diferenciación y por ello de mejora en la generación de ingresos a través de los procesos de gestión de las relaciones con sus grupos de interés. Sin olvidar a este respecto que una organización difícilmente logrará sus objetivos si previamente no ha logrado la satisfacción de sus propios trabajadores (Fornell, 2000).

De hecho, sin llegar a confundir el fin con el medio, la responsabilidad social responde a una concepción de la empresa como institución social que tiene un objetivo, satisfacer 
necesidades humanas y un medio concreto para hacerlo: el beneficio económico. Así, aunque cohabiten múltiples concepciones de responsabilidad social empresarial, el elemento común a todas ellas es la necesidad de tener en cuenta los posibles impactos de la actividad de la empresa en sus grupos de interés, en la medida que con ello garantice la maximización de los potenciales beneficios, y no así los daños. En definitiva, como recogen Blanchard y Peale (1990:102): "dirigir una empresa sólo por los beneficios es como jugar al tenis con la mirada puesta en el marcador y no en la pelota".

En el marco de la teoría de la responsabilidad social empresarial en la actualidad existen una serie de variables comunes. Entre éstas, quizás la más relevante es la que otorga a la respuesta empresarial un carácter voluntario, no impuesto desde la reglamentación. Si bien, parece adecuado advertir la importancia de compartir estándares homogéneos. En este sentido "existen riesgos de involución en la RSE si, como parece, se afianza una dispersión de diferentes estándares internacionales en torno a los EEUU y a la UE, debilitando la fuerza del Global Reporting Initiative (GRI) como estándar de referencia mundial, que ha costado mucho años y esfuerzo afianzar" (Olcese 2013:11). A ésta se añade el hecho de entender la responsabilidad social empresarial como un elemento globalizador en la actuaciones de las empresas, desde la actividad básica económica hasta su participación en el desarrollo cívico.

En todo caso la responsabilidad social empresarial debe ser entendida como un concepto dinámico y en desarrollo, en similitud con el capital social. Por esta razón se hace necesario caracterizarlo en la medida que pretendemos visualizar su verdadera dimensión. En este sentido consideramos que podemos referenciarlo como: integral, gradual y proporcional. Integral por cuanto engloba al conjunto de decisiones y actividades de la empresa y no se sitúa como un elemento complementario y al margen de las mismas. Gradual en la medida que el desarrollo empresarial en esta material va implícito al propio avance cívico del conjunto de la sociedad. Por último, al hablar de proporcionalidad es lógico interpretarla en la medida que la responsabilidad empresarial puede ser acometida por cualquier tipo de empresa sin importar su tamaño.

Como hemos comprobado, la responsabilidad social empresarial ha sido estudiada tanto desde el ámbito empresarial como desde el académico y sus enfoques son variados. Incluso dentro de la academia veíamos que los enfoques que la definen eran diversos. Según Garriga y Melé (2004), existen cuatro grandes grupos de teorías dentro de las cuáles podría circunscribirse: las instrumentales, las políticas, las integrativas y las éticas.

El enfoque instrumental lo componen aquellos autores que entienden la responsabilidad social como un elemento que proporciona ventajas competitivas. Dicho de otra forma, en este grupo estarían las empresas que únicamente suscriben su comportamiento ético siempre que les facilite un mejor posicionamiento en el mercado y la obtención de beneficios. Por su parte, el grupo de las teorías políticas se centra en el estudio del poder de las empresas en la sociedad, particularmente en lo que se refiere a su influencia en la política. Las teorías integrativas se centran en la preocupación de las empresas por dar respuesta a las demandas de la sociedad a través de sus grupos de interés. Por último, el enfoque ético se circunscribe a las teorías que analizan la responsabilidad ética frente a la sociedad.

De estos cuatro enfoques, dos son los que en la actualidad han adquirido más importancia, el instrumentalista y el integrativo. En lo que corresponde a las teorías instrumentalistas, se considera que debido al desarrollo cívico de las sociedades la empresa debe potenciar su responsabilidad social en la medida que ésta le ayuda a la consecución de sus objetivos económicos y por lo tanto a la obtención de ganancias. Es decir, la importancia que han adquirido determinados grupos de interés será la que determine el camino de las iniciativas sociales de la empresa, por cuanto influirán en la obtención de ganancias. En definitiva, la 
atención de las exigencias sociales irá en la medida de su importancia para conseguir los objetivos económicos de las empresas, abandonando aquellos otros que nos sean prioritarios en sus trasposición como beneficios (Hilman y Keim, 2001).

En contraposición a las teorías instrumentalistas se ha fortalecido el enfoque integral. Esta visión está basada en los aportes realizados por la teoría stakeholders de Freeman (1984), en las cuales la gestión de las demandas de los grupos de interés se concibe desde una perspectiva de integración en la actividad de la empresa. En otras palabras, es la forma de entender a las personas como sujetos de derecho, frente a la postura que llega a incurrir en medios no éticos por conseguir fines éticos. Nos encontramos entre la concepción de la ética deontológica en contraposición a la ética teleológica.

$\mathrm{Al}$ igual que encontramos dos perspectivas antagónicas en la teorización de la responsabilidad social empresarial, en el ámbito empresarial existen dos visiones enfrentadas: la corriente altruista frente a la perspectiva obligacionista. En este sentido, Ackerman (1975) llega a diferenciar entre obligación social, responsabilidad social y reacción social. Para él la primera está sujeta a la respuesta de cara a las fuerzas del mercado, la segunda se sitúa por encima de las obligaciones económicas y legales en el plano de corresponsabilidad de los valores sociales; y en el caso de la última iría a una iniciativa de carácter proactivo al adaptar el comportamiento empresarial a las necesidades sociales.

\section{CONCLUSIÓN}

En definitiva, podemos referirnos a que la responsabilidad social empresarial hace referencia al concepto y la práctica de cómo las empresas se relacionan e impactan en la sociedad, guardando relación con otras muchas cuestiones, entre otras: la filantropía, las donaciones, la acción social, la ciudadanía empresarial, las relaciones laborales, el desempeño social, la inversión social y las relaciones comunitarias. De hecho, "la responsabilidad social empresarial ha sido denominada la contribución de las empresas al desarrollo sostenible" (CSI 2008). Es decir, siguiendo la definición más ampliamente utilizada de desarrollo sostenible, surgida de la Comisión Brundtland de la ONU en 1987, sería el desarrollo que satisface las necesidades de la generación presente sin comprometer la capacidad de generaciones futuras para satisfacer sus propias necesidades.

\section{BIBLIOGRAFÍA}

ACKERMAN, R.W. (1975). The social Challenge to Business. Cambridge: Harvard University Press. BARON, D. (2001). "Private Politics, Corporate Social Responsibility and Integrated Strategy", Journal of Economics and Management Strategy, 10 (1): 745-765.

BLANCHARD, K. y VINCENT PEALE, N. (1990). El poder ético del directivo. Barcelona: Grijalbo. BRUNDTLAND, G. H (1987). Commission Report: World Commission on Environment and Development, Our Common Future. New York: Oxford University Press.

BUCHHOLZ, R.A. (1991). "Corporate responsibility and the good society: From economics to ecology", Business Horizons, 34 (14):19-32.

BUCHHOLZ, R.A. (1990). Essentials of Public Policy for Management. Englewoods Cliff, NJ: Prentice Hall.

CARROLL, A. (1993). Business and Society: Ethics and stakeholder Management. Cincinnati: SouthWestern Publishing. 
CARROLL, A. (1979). "A three dimensional Conceptual model of corporate performance", Academy of Management Review, 4(4): 497-505.

CE (2011). Comunicación de la Comisión al Parlamento Europeo, al Consejo, Al Comité Económico y Social Europeo y al Comité de la Regiones, Estrategia renovada de la UE para 2011-2014 sobre la responsabilidad social de las empresas, COM/2011/0681/final, accesible en http://eur-lex.europa. eu/legal-content/ES/TXT/PDF/?uri=CELEX:52011DC0681\&from=ES [consultado 18/12/ 2014].

COMISIÓN DE LAS COMUNIDADES EUROPEAS (2001). Libro Verde: fomentar un marco europeo para la responsabilidad social de las empresas. Bruselas: Comisión de las Comunidades Europeas, accesible en http://www.igualdadenlaempresa.es/enlaces/webgrafia/docs/fomentar-un-marcoeuropeo-para-la-responsabilidad-social-de-las-empresas-2001.pdf [consulta 12/11/2014]

CSI (2008). Guía sindical sobre las directrices para la elaboración de memorias de sostenibilidad de la iniciativa GRI, Confederación Sindical Internacional, accesible en http://www.observatorio-rse.org.es/ Publicaciones/MemoriasSostenibilidad.pdf [consulta 115/11/2014].

CLARKSON, M. (1995). "A stakeholder Framework for analyzing and evaluating corporative social performance", Academy of Management Journal, 20 (1): 92-117.

COMISIONES OBRERAS (2009). Conclusiones Jornadas Responsabilidad Social de las Empresas, noviembre, Seminario $1^{\circ}$ Mayo, (ejemplar multicopiado) Huelva: Fundación Sindical de Estudios.

CONFEDERACIÓN EUROPEA DE SINDICATOS (2005). "Resolución sobre RSE", Seminario: La

dimensión laboral de la responsabilidad social empresarial en España, (ejemplar multicopiado),

Confederación Europea de Sindicatos, Madrid, Fundación $1^{\circ}$ de Mayo.

CROWTHER, D. (2004). "Corporate social reporting: genuine action or Window dressing?" en D. Crowther y L. Rayman-Bacchus (eds.) Perspectives on corporative social responsibility, corporative social responsibility series. Aldershot: Ashgate, pp.140-160.

DAVIS, K. (1979). "The case for and against business assumption of social responsibilities", Academy Journal, 16: 312-322.

DELORS, J.; SANTER, J., et al. (2008). "Esta crisis financiera no es fruto del azar", Le Monde, París, 21 mayo.

DONALSON, T. y DUNFEE, T. W. (1999). Ties that bind: A social contracts approach to Business ethics. Cambridge, MA: Harvard Business School Press.

FORNELL, C. (2000). Customer asset Management, Capital Efficiency, and Shareholder Value: Performance Measurement, Past, Present and Future. Conferencia en la Universidad de Cambridge, Inglaterra, 20 de julio de 2000, accesible en: http://www.cranfield.ac.uk/som/cbp/ claeskeynote.htm.

FREEMAN, R.E. (1984). Strategic Management: A Stakeholder Approach. Boston: Pitman.

FRIEDMAN, M. (1990). "The social Responsibility of Business is to increase its profits", en W. M. Hoffman y J.M. Moore, Business Ethics. New York: McGraw Hill, pp. 153-157.

FRIEDMAN, M. (1979a). "The Social Responsibility of Business is to increase its profits", New York Times Magazine, pp. 122-126.

FRIEDMAN, M. (1979b). Does Business have social Responsibility? Madrid: Administración Moderna. FRIEDMAN, M. (1970). "Friedman Doctrine, The Social Responsibility of Business is to Increase its Profits", The New York Times Magazine, pp. 32-33 y 123-125.

FRIEDMAN, M. (1962). Capitalismo y libertad. Madrid: Rialp.

GARCÍA-MARZÁ, D. (2011). Ética empresarial: del diálogo a la confianza. Madrid: Trotta GARRIGA, E. y MELÉ, D. (2004). "Corporate Social Responsibility theories: Mapping the territory", Journal of Business Ethics, 53, (1 y 2): 51-71.

HABERMAS, J. (1985). Conciencia moral y acción comunitaria. Barcelona: Península.

HILL, C.W.L. y JONES T.M. (1996). Administración Estratégica, un enfoque integrado. Colombia: McGraw-Hill.

HILMAN, A.J. y KEIM, G.D. (2001). "Shareholder value, stakeholder Management; and social issues: What's the bottom line?", Strategic Management Journal, 22: 125-139.

KOONTZ, H. y WEILHRICH, H. (2005). Administración Estratégica, un enfoque integrado. México: McGraw-Hill.

LEVITT, T. (1958). “The Dangers of Social Responsibility”, Harvard Business Review, 36: 41-50. 
MARTIN, J.A. y NAVARRO, J.L. (2014). La Responsabilidad Social Corporativa en un escenario de crisis económica. Madrid: Colección Informes núm. 78, Fundación $1^{\circ}$ de Mayo.

MARX, K. (2001). Manuscritos de economía y filosofía. Madrid: Alianza Editorial.

MCGUIRE, J. (1963). Business and Society. New York: McGraw-Hill.

MICHAEL, B. (2003). "Corporate Social Responsibility in International Development: an overview and critique", Corporate social responsibility and Environmental Management, 10: 115-128.

OLCESE, A. (coord.) (2013). Informe sobre la responsabilidad social de la empresa en España. Una propuesta para Europa, Representación en España, Comisión Europea. Junio.

ROBBINS, S.P. y COULTER, M. (2000). Administración. México: Prentice Hall.

ROWLEY, T.J. (1997). "Moving beyond dyadic ties: A network theory of stakeholders influences", Academy of Management Review, 22 (4): 887-910.

SHELDON, O. (1923). The philosophy of management. London: Sir Issac Pitman \& Sons.

STIGLITZ, J. (2006). Cómo hacer que la globalización funcione. Madrid: Taurus.

\section{Breve currículo:}

\section{Vicente Sánchez Jiménez}

Doctor en Economía por la UCM, Máster en Dirección de Empresas y Máster en Gestión del Conocimiento, Recursos Humanos y Capital social por la UPM, Máster en Políticas de Igualdad por la URJC, Máster en Gestión Medioambiental por la USC y Máster en Salud Laboral por la UAM, Certificado en Aptitud Pedagógica, Licenciado en Ciencias del Trabajo y Diplomado en Relaciones Laborales por la UCM. Ha impartido conferencias en diversas universidades españolas, publicado varios libros sobre responsabilidad social empresarial, dirigido seminarios en los Cursos de Verano de El Escorial de la UCM y es miembro del Consejo de redacción de Cuadernos de Relaciones Laborales. 